\title{
Carbapenem Resistance Profiles of Pathogenic Escherichia coli in Uganda
}

\author{
Kenneth Ssekatawa, Denis K. Byarugaba, Jesca L. Nakavuma, Charles D. Kato, Francis Ejobi, \\ Robert Tweyongyere, and Eddie M. Wampande
}

\section{ABSTRACT}

Escherichia coli has been implicated as one of the main etiological agents of diarrhea, urinary tract infections, meningitis and septicemia worldwide. The ability to cause diseases is potentiated by presence of virulence factors. The virulence factors influence the capacity of $E$. coli to infect and colonize different body systems. Thus, pathogenic $E$. coli are grouped into DEC strains that are mainly clustered in phylogenetic group B1 and A; ExPEC belonging to $\mathrm{A}, \mathrm{B} 2$ and $\mathrm{D}$. Coexistence of virulence and beta-lactamase encoding genes complicates treatment outcomes. Therefore, this study aimed at presenting the carbapenem resistance $(\mathrm{CR})$ profiles among pathogenic $\mathrm{E}$. coli. This was a retrospective cross-sectional study involving use of 421 archived $E$. coli clinical isolates collected in $\mathbf{2 0 1 9}$ from four Uganda tertiary hospitals. The isolates were subjected to antibiotics sensitivity assays to determine phenotypic resistance. Four sets of multiplex PCR were performed to detect CR genes, DEC pathotypes virulence genes, EXPEC PAI and the E. coli phylogenetic groups. Antibiotic susceptibility revealed that all the $421 \mathrm{E}$. coli isolates used were MDR as they exhibited $100 \%$ resistance to more than one of the first-line antibiotics. The study registered phenotypic and genotypic CR prevalence of $22.8 \%$ and $33.0 \%$ respectively. The most predominant gene was blaOXA-48 with genotypic frequency of $33.0 \%$, then blavim $(21.0 \%)$, blaimp $(16.5 \%)$, blaKPC $(14.8 \%)$ and blandM $(14.8 \%)$. Spearman's correlation revealed that presence of CR genes was highly associated with phenotypic resistance. Furthermore, of 421 MDR E. coli isolates, $\mathbf{1 9 . 7 \%}$ harboured DEC virulence genes, where EPEC recorded significantly higher prevalence $(\mathbf{1 0 . 8 \%})$ followed by S-ETEC $(3.1 \%)$, STEC (2.9\%), EIEC (2.0\%) and L-ETEC (2.0\%). Genetic analysis characterized 46.1\% of the isolates as ExPEC and only PAI IV536 $(33.0 \%)$ and PAI IICFT073 $(13.1 \%)$ were detected. Phylogenetic group B2 was predominantly detected $(41.1 \%)$, followed by $\mathrm{A}(30.2 \%), \mathrm{B} 1(21.6 \%)$, and $\mathrm{D}(\mathbf{7 . 1 \%})$. Furthermore, $38.6 \%$ and $23.1 \%$ of the DEC and ExPEC respectively expressed phenotypic resistance. Our results exhibited significant level of CR carriage among the MDR DEC and ExPEC clinical isolates belonging to phylogenetic groups $B 1$ and $B 2$ respectively. Virulence and $C R$ genetic factors are mainly located on mobile elements. Thus, constitutes a great threat to the healthcare system as this promotes horizontal gene transfer.

Keywords: Carbapenem resistance, Virulence genes, Pathogenicity islands, Pathogenic E. coli, E. coli phylogenetic groups.
Published Online: April 07, 2021

ISSN: 2684-5199

DOI: $10.24018 /$ ejbio.2021.2.2.171

Kenneth Ssekatawa

College of Veterinary Medicine Animal

Resources and Biosecurity, Makerere University, Kampala, Uganda.

Department of Biochemistry, Faculty of Biomedical Sciences, Kampala International University-Western Campus, Bushenyi, Uganda.

African Center Excellence in Materials Product Development and Nanotechnology (MAPRONANO ACE), College of Engineering Design Art and Technology, Makerere University, Kampala, Uganda.

(e-mail: Kssekatee@ gmail.com) Denis K. Byarugaba

College of Veterinary Medicine Animal Resources and Biosecurity, Makerere University, Kampala, Uganda.

(e-mail: dkb@covab.mak.ac.ug)

Jesca L. Nakavuma

College of Veterinary Medicine Animal Resources and Biosecurity, Makerere University, Kampala, Uganda.

(e-mail: jesca.nakuvuma ${ }^{\circledR}$ gmail.com)

Charles D. Kato

College of Veterinary Medicine Animal Resources and Biosecurity, Makerere University, Kampala, Uganda.

(e-mail: katodrago@gmail.com) Francis Ejobi

College of Veterinary Medicine Animal Resources and Biosecurity, Makerere University, Kampala, Uganda.

(e-mail: ejobifrancis@gmail.com)

Robert Tweyongyere

College of Veterinary Medicine Animal Resources and Biosecurity, Makerere University, Kampala, Uganda.

(e-mail: tmrobert966@ gmail.com)

Eddie M. Wampande*

College of Veterinary Medicine Animal

Resources and Biosecurity, Makerere

University, Kampala, Uganda.

(e-mail: wamps@ covab.mak.ac.ug)

*Corresponding Author

\section{INTRODUCTION}

Escherichia coli is one of the most prevalent commensals of the human gastro-intestinal tract (GIT) microbiotas. However, some E. coli are pathogenic. Pathogenic E. coli comprises of diarrheagenic E. coli (DEC) [1] and Extraintestinal pathogenic E. coli (ExPEC) pathotypes [2]. Diarrheagenic pathotypes are responsible for all gastrointestinal tract $E$. coli infections most importantly diarrhea. Diarrhea is one of the principal causes of illness and 
death among children under 5 years in developing countries and DEC pathotypes account for the biggest percentage. Reaching protective immunity against DEC in children is hard as DEC is composed of a wide range of pathotypes, hence variant antigens. Extra-intestinal pathogenic E. coli is accountable for all E. coli associated infections outside the gastrointestinal tract, such as meningitis, urinary tract infections (UTI), pneumonia, septicemia, among others [3-5]. An alarming prevalence of bacterial UTI has been registered in primary healthcare. Escherichia coli has been implicated to be the main cause of both community and nosocomial acquired UTI worldwide.

Diarrheagenic E. coli are grouped into eight pathotypes basing on the virulence factors responsible for their pathogenicity. These include Enteropathogenic E. coli (EPEC), Enteroinvasive E. coli (EIEC), Enteroaggregative $E$. coli (EAEC), Enterotoxigenic E. coli (ETEC), Diffusely Adherent E. coli (DAEC), Shiga toxin-producing E. coli (STEC) also commonly known as enterohemorrhagic E. coli (EHEC) or Verotoxigenic E. coli (VTEC), the newly identified adherent invasive $E$. coli (AIEC) which is alleged to been associated with Crohn's disease but not with any diarrheagenic infections and a hybrid pathotype known as enteroaggregative hemorrhagic E. coli (EAHEC) carrying STEC and EAEC virulence genetic determinants [3]. Thus, pathogenic DEC encompasses a genetically heterogeneous family of $E$. coli with a plastic genome. Several research articles suggest that each pathotype possesses and codes for distinctive virulence and colonization determinants harboured in their genomes distinguishing them from other pathotypes and non-virulent strains. These virulence factors for each pathotype are encoded for by conserved genes and are restricted within geographical boundaries [6, 7]. Therefore, molecular typing of Escherichia coli to identify the different DEC pathotypes can be achieved by targeting the virulence genes. These virulence genes include: eae for typing of EPEC; stx for STEC/EHEC; est for ts-ETEC; elt for tl-ETEC, aggR for EAEC; ipaH for EIEC. eae gene is translated into Intimin polypeptide which is the key factor for attaching and effacing lesions; stx gene encodes for the Shigalike toxin; elt and est genes are translated into Thermolabile and Thermostable toxins respectively; ipa $H$ gene accounts for invasion capacity and $\operatorname{aggR}$ gene is translated into a transcriptional activator protein of aggregative adherence fimbriae [8].

The most clinically significant pathotypes of ExPEC are uropathogenic E. coli (UPEC) responsible for UTIs and neonatal meningitis $E$. coli, (NMEC) causing meningitis and septicemia [9]. ExPEC pathogenicity is accounted for by presence of virulence factors encoding genes located either on plasmids or chromosomes. These virulence genes are characteristically positioned in particular regions known as pathogenicity islands (PAI) if found on the chromosome [10]. Therefore molecular typing of ExPEC pathotypes can be based on multiplex PCR amplification of PAI markers previously characterized in UPEC chromosomal genes encoding virulence factors such as hemolysins (hlyA and hlyF), cytotoxic necrotizing factors ( $\mathrm{cnf} 1$ and $\mathrm{cnf} 2$ ), colicin $\mathrm{V}$ (cvaC), aerobactin (iutA), yersiniabactin (fyuA), salmochelin (iroN), P-fimbriae (papC and papG), S-fimbrial adhesin ( $\mathrm{sfaA}$ and sfaS), afimbrial adhesin (afa), serum resistance (iss and traT), brain microvascular endothelium invasion (ibe10), K1 capsule (kpsII and K1), and ompT outer membrane protein (ompT) [11, 12].

Furthermore, PCR analysis clusters E. coli strains into A, $\mathrm{B} 1, \mathrm{~B} 2$, and D phylogenetic groups due to the presence of the chuA and yjaA genes as well as TSPE4.C2 DNA fragment [13]. The intestinal pathogenic E. coli strains belong to groups A, B1 and D, extraintestinal pathogenic E. coli strains are generally placed under groups B2 and D, while commensal $E$. coli strains belong to groups A and B1 $[13,14]$.

High levels antibiotic resistance in Enterobacteriaceae is of great concern to the healthcare system. Escherichia coli like other Enterobacteriaceae has evolved to acquire different mechanisms of antibiotic resistance which confer protection to lethal doses of different classes of antibiotics. Carbapenems are the most suitable antibiotics used in the treatment of multidrug resistant (MDR) gram-negative bacteria infections. Studies have documented high prevalence of carbapenem resistant Enterobacteriaceae (CRE) in Uganda $[15,16]$. However, the carbapenem resistance profiles of DEC and ExPEC human isolates have not been investigated, yet for meaningful treatment outcomes and prescription decisions, knowledge about pathogen susceptibility patterns to antibiotics in question is very important. Thus, this study was aimed at profiling the carbapenem resistance profiles of intestinal and extraintestinal human pathogenic E. coli isolates for genetic markers allied with DEC and ExPEC strains. The study relied on the screening for DEC genetic markers, PAI associated sequences for ExPEC and determination of phylogenetic group and genetic determinants of carbapenem resistance (CR).

\section{MATERIALS AND METHODS}

\section{A. Study Design, Site and Source of Bacteria Isolates}

This was a cross sectional-laboratory-based study conducted at the Microbiology Laboratory and Molecular Biology Laboratory, College of Veterinary Medicine Animal Resources and Biosecurity (CoVAB) Makerere University. The study involved use of archived MDR Escherichia coli samples isolated between January and December 2019 from clinical specimens in the Microbiology Laboratories of Mulago National Referral Hospital (MNRH), Mbale Regional Referral Hospital (MRRH), Mbarara Regional Referral Hospital (MBRRH) and Kampala International University Teaching Hospital (KIU-TH). The samples were transported in peptone water to the Microbiology Laboratory, CoVAB. Overnight cultures of E. coli were prepared by pipetting $1 \mathrm{ml}$ of peptone water containing each isolate into $49 \mathrm{ml}$ of Luria-Bertani (LB) broth. Glycerol stocks of the isolate were prepared by adding $500 \mu \mathrm{l}$ of the overnight LB culture to $500 \mu \mathrm{L}$ of $50 \%$ glycerol in a $2 \mathrm{ml}$ screw top tube and mixed gently mix. The screw tubes were stored at $-80{ }^{\circ} \mathrm{C}$ until further use.

\section{B. Biochemical Assays to Confirm the Identity of E. coli}

To confirm the identity of each isolate, Microgen (Microbiology International) kits for biochemical assays were employed using procedures described by the manufacturer (www.microgenbioproducts.com). 


\section{Screening for Carbapenem Susceptibility}

This was achieved using the Kirby Bauer Disk Diffusion method and the results obtained were interpreted according to Clinical and Laboratory Standards Institute (CLSI) guidelines [17]. Ampicillin (AMP) $25 \mu \mathrm{g}$, Amoxicillin/clavulanic acid (AMO) $\quad 20 / 10 \quad \mu \mathrm{g}, \quad$ trimethoprim-sulfamethoxazole (TMP/SMX) 1.25/23.75 $\mu \mathrm{g}$, Ciprofloxacin (CIP) $5 \mu \mathrm{g}$, Cefuroxime (CXM) $30 \mu \mathrm{g}$, Temocillin (TEM) $30 \mu \mathrm{g}$, Piperacillin-tazobactum (TPZ) $110 \mu \mathrm{g}$, Cefoxitin (FOX) 30 $\mu \mathrm{g}$, Cefipime (FEP) 30 $\mu \mathrm{g}$, Ceftriaxone (CRO) $30 \mu \mathrm{g}$, Ceftazidime (CAZ) $30 \mu \mathrm{g}$, Cefotaxime (CTX) $30 \mu \mathrm{g}$, Ertapenem (ERT) $10 \mu \mathrm{g}$, Meropenem (MEM) $10 \mu \mathrm{g}$ and Imipenem (IMI) $10 \mu \mathrm{g}$ (Oxoid United Kingdom) carbapenem antibiotics disks were used. The turbidity of overnight Escherichia coli broth was adjusted using peptone water to a standard uniform concentration of 0.5 McFarland. Each $E$. coli isolate was inoculated on Mueller Hinton agar (Oxoid, United Kingdom) plates. Three antibiotic discs were placed about $2.0 \mathrm{~cm}$ apart and from the edge of plates, then incubated at $37{ }^{\circ} \mathrm{C}$ for 24 hours. The diameter of the zones of growth inhibition were scored in millimeters. For quality control, $E$. coli ATCC 25922 was used as a susceptible strain and Klebsiella pneumoniae ATCC BAA-1705 as a positive control.

\section{DNA Extraction}

Pure colonies of $E$. coli from different samples were selected and each sub-cultured in $5 \mathrm{ml}$ of Luria-Bertani broth using sterile inoculating loop. The bacterial suspension was incubated in a shaker incubator at $37^{\circ} \mathrm{C}$ for $24 \mathrm{hrs}$. Then, 1 $\mathrm{ml}$ of bacterial suspension was transferred into a $1.5 \mathrm{ml}$ Eppendorf tube, centrifuged at 10,000 rpm for 10 minutes. The supernatant was discarded, and the pellet was resuspended in $200 \mu \mathrm{l}$ of Gram-negative bacteria lysis buffer provided in the Qiagen DNA extraction. Bacterial total genomic DNA was extracted following the Qiagen DNA extraction protocol and stored at $-20{ }^{\circ} \mathrm{C}$ until further use.

\section{E. Molecular Characterization of Virulence Genes and Carbapenem Resistance Determinants}

Molecular identification of carbapenem resistance determinants and virulent genes in Escherichia coli was carried out using multiplex PCR. Primers used for molecular characterization were obtained from Eurofins Genomics AT $\mathrm{GmbH}$ and PCR amplification was performed in a Bio-Rad PTC-200 Thermal Cycler (Bio-Rad, Hercules, CA, USA)

\section{F. Multiplex PCR Amplification of Carbapenem Resistance Genes}

The existence of carbapenem resistance genetic determinants was determined using primers targeting $b l a_{\mathrm{VIM}}$, bla $a_{\mathrm{IMP}}, b_{\text {KPC }}, b_{\mathrm{K}} a_{\mathrm{OXA}}-48$, and bla $a_{\mathrm{NDM}}$ that carbapenemase encoding genes, Table I. For co-amplification of the target genes, multiplex PCR was conducted by adapting methods used by Dallenne et al. [18]. Briefly, $2.5 \mu 1$ of template DNA $(100 \mathrm{ng} / \mu \mathrm{l})$ was added to $47.5 \mu \mathrm{l}$ PCR mix containing 200 $\mu \mathrm{M}$ dNTPs (Biomatik, USA), $0.5 \mu \mathrm{M}$ of each primer pair and 1X PCR Buffer (1.5 mM MgCl $2,10 \mathrm{mM}$ Tris-HCl, $\mathrm{pH} 8.3 / 50$ $\mathrm{mM} \mathrm{KCl}$ ) (Biomatik USA) and $1.2 \mu \mathrm{l}$ of $1 \mathrm{U}$ Taq DNA Polymerase. Amplification was performed as follows; preliminary denaturation at $95{ }^{\circ} \mathrm{C}$ for 5 minutes; then denaturation at $95{ }^{\circ} \mathrm{C}$ for 30 seconds; annealing at $56{ }^{\circ} \mathrm{C}$ for
30 seconds and elongation at $72^{\circ} \mathrm{C}$ for 1 minute; and a final elongation at $72{ }^{\circ} \mathrm{C}$ for 10 minutes. For quality assurance positive and negative control isolates were obtained as a kind donation from the Microbiology Laboratory, MNRH. Antibiotics susceptible DSMZ 9377 Klebsiella pneumoniae was used as a negative control for all genes. Klebsiella pneumonia Nr.8 for NDM-1, Klebsiella pneumoniae 714 for OXA-48, Klebsiella pneumoniae 211 (T) for KPC, P. aeruginosa for IMP (Positive control strains from the Institute of Microbiology, Giessen, Germany) and E. coli for the VIM gene, obtained from RESET research collaboration [19] were used as positive controls.

\begin{tabular}{|c|c|c|c|}
\hline Gene & $\begin{array}{c}\text { Primer sequence }\left(5^{1}-\right. \\
\left.3^{1}\right)\end{array}$ & $\begin{array}{c}\text { Band } \\
\text { size } \\
\text { (Bp) }\end{array}$ & Reference \\
\hline$B l a_{\mathrm{KPC}}$ & $\begin{array}{l}\text { F-ATG TCA CTG } \\
\text { TAT CGC CGT CT } \\
\text { R-TTT TCA GAG } \\
\text { CCT TAC TGC CC }\end{array}$ & 538 & [18] \\
\hline$B l a_{\mathrm{IMP}}$ & $\begin{array}{c}\text { F-TGA GCA AGT } \\
\text { TAT CTG TAT TC } \\
\text { R-TTA GTT GCT } \\
\text { TGG TTT TGA TG }\end{array}$ & 139 & [18] \\
\hline$B l a_{\mathrm{VIM}}$ & $\begin{array}{c}\text { F-GAT GGT GTT } \\
\text { TGG TCG CAT A } \\
\text { R-CGA ATG CGC } \\
\text { AGC ACC AG }\end{array}$ & 390 & [18] \\
\hline$B l a_{\mathrm{NDM}}$ & $\begin{array}{l}\text { F-GGT TTG GCG } \\
\text { ATC TGG TTT TC } \\
\text { R-CGG AAT GGC } \\
\text { TCA TCA CGA TC }\end{array}$ & 822 & [20] \\
\hline$B l a_{\text {OXA-48 }}$ & $\begin{array}{c}\text { F-TTG GTG GCA } \\
\text { TCG ATT ATC GG } \\
\text { R- GAG CAC TTC } \\
\text { TTT TGT GAT GGC }\end{array}$ & 281 & [18] \\
\hline
\end{tabular}

\section{G. Multiplex PCR Components and Conditions for E. coli Pathotyping}

Virulence genes eae for EPEC; stx for STEC/EHEC; est for ts-ETEC; elt for tl-ETEC; $a g g R$ for EAEC; ipaH for EIEC were amplified by multiplex PCR to characterize the different pathogenic bacteria using primers outlined in Table II [8]. Five E. coli strains INCQS 00181 (CDC 055 - EPEC), INCQS 00171 (CDC EDL - 933 - EHEC) and INCQS 00170 (CDC EDL - 1284 - EIEC) from Centre for disease control and prevention belonging to the five categories of pathogenic E. coli were used as control [20]. Multiplex PCR reaction was performed using [21] modified method to enable the concurrent amplification of all the target genes. A final PCR volume of $50 \mu \mathrm{l}$ containing $5 \mu \mathrm{l}$ of $100 \mathrm{ng}$ DNA sample, 25 $\mu \mathrm{l}$ of 1X PCR Buffer mixed with $\mathrm{MgCl}_{2}(1.5 \mathrm{mM}), 1.2 \mu \mathrm{l}$ of 1U Taq DNA Polymerase and dNTPs $(200 \mu \mathrm{M})$ plus $0.5 \mu \mathrm{M}$ each primer pair for DEC pathotypes. Sterile distilled deionized water was used to top up to $50 \mu \mathrm{l}$. The PCR was performed under the following condition. An initial denaturation at $95{ }^{\circ} \mathrm{C}$ for 5 minutes then 30 amplification cycles at $95{ }^{\circ} \mathrm{C}$ for 30 second, $50{ }^{\circ} \mathrm{C}$ for 30 second, $72{ }^{\circ} \mathrm{C}$ for 1 minute, and a final extension at $72{ }^{\circ} \mathrm{C}$ for 30 minutes.

\section{H. PCR Amplification of PAI Markers}

Seven different PAI markers designated as PAI I536, PAI

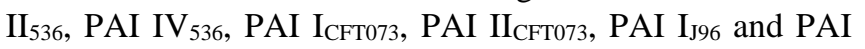


$\mathrm{II}_{\mathrm{J} 96}$ have been previously characterized in UPEC [22], Table III. Thus, the multiplex PCR used in the detection of PAI Markers, contained $2.5 \mu \mathrm{l}$ of template DNA (100 ng/ $\mu \mathrm{l}), 1 \mathrm{U}$ Taq DNA polymerase (Biomatik) in 1X PCR buffer (Biomatik), $200 \mu \mathrm{M}$ of each dNTP, $2.5 \mathrm{mM} \mathrm{MgCl}$, and
$0.5 \mu \mathrm{M}$ of each primer, Table III. The program consisted of initial denaturation at $94{ }^{\circ} \mathrm{C}$ for $5 \mathrm{~min}$, followed by 30 cycles of $94{ }^{\circ} \mathrm{C}$ for 1 minute, $55{ }^{\circ} \mathrm{C}$ for 1 minute and $72{ }^{\circ} \mathrm{C}$ for 1 minute, with a final extension step at $72{ }^{\circ} \mathrm{C}$ for 10 minutes [22]. The positive control used in the PCR was J96 O4:K6.

TABLE II: GENES AND THEIR PRIMER SEQUENCES FOR MOLECULAR TYPING OF E. COLI (ADOPTED FROM [23])

\begin{tabular}{|c|c|c|c|c|}
\hline Gene & Primer Sequence $(5,-3)$ & $\begin{array}{c}\text { Size of } \\
\text { amplicon }(\mathrm{Bp})\end{array}$ & $\begin{array}{l}\text { Annealing } \\
\text { Temp }\left({ }^{\circ} \mathrm{C}\right)\end{array}$ & Reference \\
\hline eae & $\begin{array}{l}\text { CCCGAATTCGGCACAAGCATAAGC } \\
\text { CCCGGATCCGTCTCGCCAGTATTCG }\end{array}$ & 881 & 50 & [24] \\
\hline stx & $\begin{array}{l}\text { GAGCGAAATAATTTATATGTG } \\
\text { TGATGATGGCAATTCAGTAT }\end{array}$ & 518 & 50 & [25] \\
\hline est & $\begin{array}{l}\text { ATTTTTMTTTCTGTATTRTCTT } \\
\text { CACCCGGTACARGCAGGATT }\end{array}$ & 190 & 50 & [26] \\
\hline elt & $\begin{array}{l}\text { GGCGACAGATTATACCGTGC } \\
\text { CGGTCTCTATATTCCCTGTT }\end{array}$ & 450 & 50 & [26] \\
\hline paH & $\begin{array}{c}\text { GTTCCTTGACCGCCTTTCCGATACCGTC } \\
\text { GCCGGTCAGCCACCCTCTGAGAGTAC }\end{array}$ & 619 & 50 & [27] \\
\hline $\operatorname{aggR}$ & $\begin{array}{c}\text { GTATACACAAAAGAAGGAAGC } \\
\text { ACAGAATCGTCAGCATCAGC }\end{array}$ & 254 & 50 & [28] \\
\hline
\end{tabular}

TABLE III: OLIGONUCLEOTIDES USED TO AMPLIFY PAI MARKERS HARBORING VIRULENCE GENETIC DETERMINANTS

\begin{tabular}{|c|c|c|c|c|}
\hline PAI markers & Primer sequence (5'-3') & $\begin{array}{l}\text { Amplicon } \\
\text { size (bp) }\end{array}$ & $\begin{array}{l}\text { Virulent factors expressed by } \\
\text { genes harboured by PAI markers }\end{array}$ & Reference \\
\hline PAI I $I_{536}$ & $\begin{array}{c}\text { TAA TGC CGG AGA TTC ATT GTC } \\
\text { AGG ATT TGT CTC AGG GCT TT }\end{array}$ & 1800 & $\begin{array}{l}\alpha \text {-Haemolysin, CS12 fimbriae, } \\
\text { and F17-like fimbrial adhesin }\end{array}$ & {$[22]$} \\
\hline PAI II $I_{536}$ & $\begin{array}{l}\text { CAT GTC CAA AGC TCG AGC C } \\
\text { CTA CGT CAG GCT GGC TTT G }\end{array}$ & 1000 & $\begin{array}{l}\alpha \text {-Haemolysin and P-related } \\
\text { fimbriae }\end{array}$ & {$[22]$} \\
\hline PAI IV $_{536}$ & $\begin{array}{l}\text { AAG GAT TCG CTG TTA CCG GAC } \\
\text { TCG TCG GGC AGC GTT TCT TCT }\end{array}$ & 300 & Yersiniabactin siderophore system & {$[22]$} \\
\hline PAI ICFT073 & $\begin{array}{l}\text { GGA CAT CCT GTT ACA GCG CGC A } \\
\text { TCG CCA CCA ATC ACA GC GAA C }\end{array}$ & 930 & $\begin{array}{c}\alpha \text {-Haemolysin, P-fimbriae, and } \\
\text { aerobactin }\end{array}$ & [22] \\
\hline PAI IICFT073 & $\begin{array}{c}\text { ATG GAT GTT GTA TCG CG } \\
\text { ACG AGC ATG TGG ATC TGC }\end{array}$ & 400 & $\begin{array}{l}\text { P-fimbriae and iron-regulated } \\
\text { genes }\end{array}$ & {$[22]$} \\
\hline PAI IJ96 & $\begin{array}{c}\text { TCG TGC TCA GGT CCG GAA TTT } \\
\text { TGG CAT CCC ACA TTA TCG }\end{array}$ & 400 & $\alpha$-Haemolysin and P-fimbriae & {$[22]$} \\
\hline PAI IIJ96 & $\begin{array}{l}\text { GGA TCC ATG AAA ACA TGG TTA ATG GG } \\
\text { GAT ATT TTT GTT GCC ATT GGT TAC C }\end{array}$ & 2300 & $\begin{array}{l}\alpha \text {-Haemolysin, Prs-fimbriae, and } \\
\text { cytotoxic necrotizing factor } 1\end{array}$ & {$[22]$} \\
\hline
\end{tabular}

TABLE IV: PRIMERS USED IN PHYLOGENETIC ANALYSIS OF E. COLI

\begin{tabular}{|c|c|c|c|c|}
\hline Gene & Primer sequence (5'-3') & $\begin{array}{l}\text { Amplicon } \\
\text { size (bp) }\end{array}$ & Protein expressed & Reference \\
\hline $\operatorname{chuA}$ & $\begin{array}{l}\text { GAC GAA CCA ACG GTC AGG AT } \\
\text { TGC CGC CAG TAC CAA AGA CA }\end{array}$ & 279 & $\begin{array}{l}\text { Hemetransport in enterohemorrhagic } \\
\text { O157:H7 E. coli }\end{array}$ & [13] \\
\hline$y j a \mathrm{~A}$ & $\begin{array}{l}\text { TGA AGT GTC AGG AGA CGC TG } \\
\text { ATG GAG AAT GCG TTC CTC AAC }\end{array}$ & 211 & Protein function unknown & [13] \\
\hline TSPE4.C2 & $\begin{array}{l}\text { GAG TAA TGT CGG GGC ATT CA } \\
\text { CGC GCC AAC AAA GTA TTA CG }\end{array}$ & 152 & $\begin{array}{l}\text { Putative DNA fragment (TSPE4.C2) } \\
\text { in E. coli }\end{array}$ & [13] \\
\hline
\end{tabular}

\section{Phylogenetic Classification}

Phylogenetic classification exhibited that the E. coli strains belonged to four groups (A, B1, B2, or D) based on the presence of the chuA and yjaA genes and the DNA fragment (TSPE4.C2). Thus, a multiplex PCR was run to determine the phylogenetic classes of the $E$. coli strains using primers targeting chuA, yjaA and TSPE4.C2 DNA sequences, Table IV. The PCR amplification was conducted by adapting [13] methods. Briefly, the PCR contained $2.5 \mu$ l of template DNA, $1 \mathrm{U}$ Taq DNA polymerase (Biomatik, USA) in 1x PCR buffer (Biomatik), $200 \mu \mathrm{M}$ dNTP, $2.5 \mathrm{mM} \mathrm{MgCl}$, and $0.8 \mu \mathrm{M}$ of each primer, Table 1. Amplification was conducted using the following PCR conditions; initial denaturation at $94{ }^{\circ} \mathrm{C}$ for 5 minutes, then 30 cycles performed at $94{ }^{\circ} \mathrm{C}$ for 5 seconds, 54 ${ }^{\circ} \mathrm{C}$ for 10 seconds, $72{ }^{\circ} \mathrm{C}$ for 30 second with a final extension step at $72{ }^{\circ} \mathrm{C}$ for 5 minutes. Phylogenic groups and subgroups were assigned depending on chuA, yjaA, and TspE4.C2 gene combinations $[13,14]$ (Table V).

TABLE V: CHUA, YJAA, AND TSPE4.C2 GENE COMBINATIONS FOR ASSIGNING OF PHYLOGENETIC GROUPS AND SUBGROUPS OF ESCHERICHIA COLI

\begin{tabular}{ccccc}
\hline TSECP4C2 & yjaA & ChuA & $\begin{array}{c}\text { Phylogenetic } \\
\text { group }\end{array}$ & $\begin{array}{c}\text { Phylogenetic } \\
\text { subgroup }\end{array}$ \\
\hline Negative & Negative & Negative & A & A0 \\
Negative & Positive & Negative & A & A1 \\
Positive & Negative & Negative & B1 & B1 \\
Negative & Positive & Positive & B2 & B22 \\
Positive & Positive & Positive & B2 & B23 \\
Negative & Negative & Positive & D & D1 \\
Positive & Negative & Positive & D & D2 \\
\hline
\end{tabular}

\section{J. Ethical Consideration}

Ethical Approval No: MHREC1611 was granted by the Research and Ethics Committee for ethical review and approval, Mulago National Referral Hospital. The Research Ethics Committee waived the need for informed consent to 
use already coded archived samples in this study.

\section{K. Data Analysis}

Data analysis was done using the SPSS version 25 (SPSS Inc., Chicago, IL). Statistical differences were computed by chi-square and Spearman's correlation. A $p$ value $\leq 0.05$ indicated substantial statistical difference.

\section{RESULtS}

\section{A. Distribution of Escherichia coli Isolates in Clinical} Specimen

We obtained a total of 618 MDR $E$. coli isolates whereby 300, 67, 142 and 109 isolates were from MNRH, MRRH, MBRRH and KIU-TH respectively. However, 206 isolates were neither viable (177) nor E. coli (29). Thus, this study used a total of 421 isolates, 205 were obtained from MNRH, 52 from MRRH, 62 from MBRRH and 102 from KIU-TH. The isolates were predominantly isolated from urine $(170 / 40.4 \%)$, then anal swabs $(103 / 24.5 \%)$, wound/pus swabs $(62 / 14.7 \%)$, blood $(28 / 6.7 \%)$, virginal swabs, (27/6.4), sputum (19/4.5\%) and tracheal aspirate (12/2.9\%), Table VI.

\section{B. Phenotypic Carbapenem Resistance Profiles}

The Kirby Bauer disk diffusion method was used to determine the susceptibility patterns of the E. coli clinical isolates according to CLSI interpretation. All the isolates demonstrated $100 \%$ resistance to Ampicillin and Amoxicillin/clavulanic acid hence were MDR, Table I. Out of the $421 \mathrm{E}$. coli clinical isolates obtained from the different tertiary hospitals, 96 were resistant to Ertapenem and out of the 96 Ertapenem resistant isolates, $43(10.2 \%)$ were resistant to both Imipenem and Meropenem. Thus, this study registered an overall phenotypic carbapenem resistance prevalence of $22.8 \%$. Furthermore, MRRH recorded the highest phenotypic carbapenem resistance prevalence of $34.6 \%$ followed by MBRRH (33.9\%), MNRH (22.0\%) and KIU-TH (11.8\%). Carbapenem resistant E. coli were largely isolated from anal swabs $(31.1 \%)$, followed by urine $(24.1 \%)$, then wound/pus swabs $(17.7 \%)$, tracheal aspirate $(16.7 \%)$, Sputum (15.8\%), blood (14.3\%) and virginal swabs (11\%), Table VI.

\section{Distribution of Carbapenemase Encoding GENES}

Pentaplex PCR amplification revealed that $33.0 \%$ (139/421) of the E. coli isolates obtained from different tertiary hospitals harbored one or more carbapenemases encoding genes. E. coli obtained from MRRH scored the highest genotypic prevalence of carbapenem resistance $(28 / 52=53.9 \%)$ followed by MBRRH $(28 / 62=45.2 \%)$, MNRH $(62 / 205=30.3 \%)$ and KIU-TH $(21 / 102=20.6 \%)$. Out of the $139 \mathrm{E}$. coli isolates that possessed carbapenem resistant genes, $18.7 \%$ (26/139) contained multiple genes. A total of 176 carbapenemases encoding genes was scored and the most predominant gene recorded was bla $a_{\text {OXA-48 }}$ at a prevalence/genotypic frequency of $13.8 \% / 33.0 \%$, tailed by bla $_{\mathrm{VIM}}(8.8 \% / 21.0 \%)$, then bla $\mathrm{IMP}_{\mathrm{IP}}(6.9 \% / 16.5 \%)$, bla $a_{\mathrm{KPC}}$ $(6.2 \% / 14.8 \%)$ and bla NDM $(6.2 / 14.8 \%)$, Tables VII and VIII.

\section{Relationship between Carbapenemase Encoding Genes and Phenotypic Resistance}

This study registered substantial variability between genotypic and phenotypic resistance. Among the carbapenemases genes encountered, bla $\mathrm{VIM}_{\mathrm{M}}$ provided phenotypic CR to $97.3 \%$ (36/37) E. coli isolates that harbored it. This was trailed by $b l a_{\mathrm{IMP}}(96.6 \%)$, bla $_{\mathrm{KPC}}(80.8 \%)$, bla $_{\mathrm{NDM}}$ (65.4\%) and bla $a_{\text {OXA-48 }}(37.9 \%)$, Table VIII. Four isolates were found to co-harbour more than one carbapenemase encoding genes, with $b a_{\mathrm{OXA}}$ and bla $a_{\mathrm{NDM}}$ co-existing in two isolates, bla $_{\mathrm{OXA}-48}$ and bla $a_{\mathrm{KPC}}$ in one isolate and bla $a_{\mathrm{OXA}-48}, b a_{\mathrm{KPC}}$ and bla $a_{\mathrm{NDM}}$ in one isolate but exhibited no phenotypic resistance, Table II. Despite of no carbapenemase encoding genes detected, a total of eight (8) isolates $(\mathrm{MNRH}=3, \mathrm{MBRRH}=3$ and $\mathrm{KIU}-\mathrm{TH}=2$ ) exhibited phenotypic carbapenem resistance.

\section{E. Relationship between Carbapenemase Encoding Genes and Phenotypic Resistance}

This study registered substantial variability between genotypic and phenotypic resistance. Among the carbapenemases genes encountered, bla $a_{\mathrm{VIM}}$ provided phenotypic CR to $97.3 \%$ (36/37) E. coli isolates that harbored it. This was trailed by $b l a_{\mathrm{IMP}}(96.6 \%)$, bla $_{\mathrm{KPC}}(80.8 \%), b l a_{\mathrm{NDM}}$ $(65.4 \%)$ and $b l a_{\text {OXA-48 }}(37.9 \%)$, Table VIII. Four isolates were found to co-harbour more than one carbapenemase encoding genes, with bla $a_{\mathrm{OXA}}$ and bla $a_{\mathrm{NDM}}$ co-existing in two isolates, $b a_{\mathrm{OXA}-48}$ and $b l a_{\mathrm{KPC}}$ in one isolate and bla $a_{\mathrm{OXA}-48}, b l a_{\mathrm{KPC}}$ and bla $a_{\mathrm{NDM}}$ in one isolate but exhibited no phenotypic resistance, Table II. Despite of no carbapenemase encoding genes detected, a total of eight (8) isolates $(\mathrm{MNRH}=3, \mathrm{MBRRH}=3$ and $\mathrm{KIU}-\mathrm{TH}=2$ ) exhibited phenotypic carbapenem resistance.

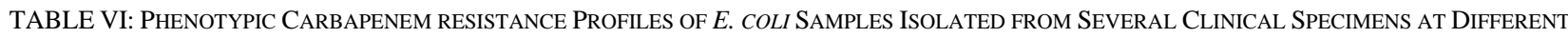

\begin{tabular}{ccccccccccccc}
\hline & \multicolumn{10}{c}{ TERTIARY HosPITALS IN UGANDA } \\
\hline \multirow{2}{*}{ Clinical Specimen } & \multicolumn{1}{c}{ MNRH } & \multicolumn{1}{c}{ MRRH } & \multicolumn{1}{c}{ MBRRH } & \multicolumn{1}{c}{ KIU-TH } & \multicolumn{2}{c}{ Total } & CR Prevalence per \\
clinical specimen $(\%)$
\end{tabular}

$\mathrm{n}=$ population or number of samples and CR stands for carbapenem resistance. 
TABLE VII: DiSTRIBUTION OF CARBAPENEM RESISTANT GENES IN E. COLI ISOLATES OBTAINED FROM DIFFERENT TERTIARY HOSPITALS IN UGANDA

\begin{tabular}{|c|c|c|c|c|c|c|c|c|c|c|c|c|c|c|c|c|c|}
\hline \multirow[b]{2}{*}{$\begin{array}{l}\text { Referral } \\
\text { Hospital }\end{array}$} & \multirow[b]{2}{*}{$\mathrm{n}$} & \multicolumn{16}{|c|}{ Carbapenemase encoding genes } \\
\hline & & $\begin{array}{l}\text { ND } \\
M\end{array}$ & KPC & IMP & OXA-48 & VIM & $\begin{array}{c}\text { NDM \& } \\
\text { OXA- } \\
48 \\
\end{array}$ & $\begin{array}{l}\text { IMP \& } \\
\text { NDM }\end{array}$ & $\begin{array}{c}\text { KPC \& } \\
\text { OXA-48 }\end{array}$ & $\begin{array}{c}\text { IMP \& } \\
\text { OXA-48 }\end{array}$ & $\begin{array}{l}\text { VIM \& } \\
\text { OXA-48 }\end{array}$ & $\begin{array}{c}\text { VIM, } \\
\text { NDM \& } \\
\text { OXA-48 } \\
\end{array}$ & $\begin{array}{c}\text { NDM, } \\
\text { KPC \& } \\
\text { OXA-48 }\end{array}$ & $\begin{array}{c}\text { IMP, } \\
\text { NDM \& } \\
\text { OXA-48 } \\
\end{array}$ & $\begin{array}{c}\text { IMP, } \\
\text { VIM } \\
\text { OXA-48 }\end{array}$ & $\begin{array}{c}\text { Total CR } \\
\text { isolates }\end{array}$ & $\begin{array}{l}\text { Prevalence } \\
(\%)\end{array}$ \\
\hline MNRH & 205 & 07 & 07 & 06 & 11 & 19 & 02 & - & 04 & - & - & 02 & 04 & - & - & 62 & 30.3 \\
\hline MRRH & 52 & 03 & 04 & 05 & 07 & 02 & - & 02 & - & & & - & - & 03 & 02 & 28 & 53.9 \\
\hline MBRRH & 62 & 02 & 03 & 03 & 09 & 04 & - & - & - & 05 & 02 & - & - & - & - & 28 & 45.2 \\
\hline KIU-TH & 102 & 01 & 04 & 03 & 07 & 06 & - & - & - & - & - & - & - & - & - & 21 & 20.6 \\
\hline Total & 421 & & & & & & & & & & & & & & & 139 & 33.0 \\
\hline
\end{tabular}

TABLE VIII: CoRRELATION BETWEEN CARBAPENEM RESISTANCE GENES AND PHENOTYPIC RESISTANCE

\begin{tabular}{|c|c|c|c|c|c|c|c|c|c|c|c|}
\hline \multirow{3}{*}{ Tertiary Hospital } & \multicolumn{10}{|c|}{ Carbapenemase encoding genes } & \multirow{3}{*}{ Total } \\
\hline & \multicolumn{2}{|c|}{ VIM } & \multicolumn{2}{|c|}{ OXA-48 } & \multicolumn{2}{|c|}{ IMP } & \multicolumn{2}{|c|}{ KPC } & \multicolumn{2}{|c|}{ NDM } & \\
\hline & $\mathrm{R}$ & $\mathrm{S}$ & $\mathrm{R}$ & $\mathrm{S}$ & $\mathrm{R}$ & $\mathrm{S}$ & $\mathrm{R}$ & $\mathrm{S}$ & $\mathrm{R}$ & $\mathrm{S}$ & \\
\hline MNRH & 21 & 0 & 9 & 14 & 6 & 0 & 12 & 3 & 9 & 6 & 80 \\
\hline MRRH & 4 & 0 & 5 & 7 & 12 & 0 & 4 & 0 & 6 & 2 & 40 \\
\hline MBRRH & 6 & 0 & 8 & 8 & 7 & 1 & 3 & 0 & 2 & 0 & 35 \\
\hline KIU & 5 & 1 & 0 & 7 & 3 & 0 & 2 & 2 & 0 & 1 & 21 \\
\hline Total & 36 & 1 & 22 & 36 & 28 & 1 & 21 & 5 & 17 & 9 & 176 \\
\hline Prevalence $(\%)$ & \multicolumn{2}{|c|}{8.8} & \multicolumn{2}{|c|}{13.8} & \multicolumn{2}{|c|}{6.9} & \multicolumn{2}{|c|}{6.2} & \multicolumn{2}{|c|}{6.2} & \\
\hline Phenotypic CR (\%) & \multicolumn{2}{|c|}{97.3} & \multicolumn{2}{|c|}{37.9} & \multicolumn{2}{|c|}{96.6} & \multicolumn{2}{|c|}{80.8} & \multicolumn{2}{|c|}{65.4} & \\
\hline Genotypic frequency (\%) & \multicolumn{2}{|c|}{21.0} & \multicolumn{2}{|c|}{33.0} & \multicolumn{2}{|c|}{16.5} & \multicolumn{2}{|c|}{14.8} & \multicolumn{2}{|c|}{14.8} & \\
\hline
\end{tabular}

R: Resistant, S: Sensitive.

TABLE IX: Distribution of PATHOgenic E. COLI AMONG THE TERTIARy Hospitals ANd Clinical SAMPLES

\begin{tabular}{|c|c|c|c|c|c|c|c|c|c|c|c|c|c|c|}
\hline & \multirow[b]{2}{*}{ Pathotype } & \multicolumn{5}{|c|}{ Tertiary hospitals } & \multicolumn{8}{|c|}{ Clinical specimens } \\
\hline & & MNRH & MRRH & MBRRH & KIU-TH & $\begin{array}{c}\text { Total/ } \\
\text { prevalence }\end{array}$ & Urine & Blood & Anal Swabs & $\begin{array}{c}\text { Wound/ pus } \\
\text { swabs }\end{array}$ & Sputum & $\begin{array}{l}\text { Tracheal } \\
\text { aspirate }\end{array}$ & $\begin{array}{c}\text { Virginal } \\
\text { swabs }\end{array}$ & $\begin{array}{c}\text { Total/ } \\
\text { Prevalence }\end{array}$ \\
\hline & eae/EPEC & $21(10.2 \%)$ & $2(3.9 \%)$ & $8(12.9 \%)$ & $11(10.8 \%)$ & $42(10.0 \%)$ & $3(1.8 \%)$ & $1(3.6 \%)$ & $37(35.9 \%)$ & $1(1.6 \%)$ & $0(0.0 \%)$ & $0(0.0 \%)$ & $0(0.0 \%)$ & $42(10.0 \%)$ \\
\hline & elt/L-ETEC & $3(1.5 \%)$ & $2(3.9 \%)$ & $1(1.6 \%)$ & $2(2.0 \%)$ & $8(2.0 \%)$ & $1(0.6 \%)$ & $0(0.0 \%)$ & $6(5.8 \%)$ & $0(0.0 \%)$ & $1((5.3 \%)$ & $0(0.0 \%)$ & $0(0.0 \%)$ & $8(2.0 \%)$ \\
\hline & est/S-ETEC & $3(1.5 \%)$ & $3(5.8 \%)$ & $4(6.5 \%)$ & $3(2.9 \%)$ & $13(3.1 \%)$ & $0(0.0 \%)$ & $0(0.0 \%)$ & $13(12.6 \%)$ & $0(0.0 \%)$ & $0(0.0 \%)$ & $0(0.0 \%)$ & $0(0.0 \%)$ & $13(3.1 \%)$ \\
\hline \multirow{3}{*}{ DEC } & stx/STEC & $4(2.0 \%)$ & $2(3.9 \%)$ & $3(4.8 \%)$ & $3(2.9 \%)$ & $12(2.9 \%)$ & $0(0.0 \%)$ & $0(0.0 \%)$ & $11(10.7 \%)$ & $0(0.0 \%)$ & $1(5.3 \%)$ & $0(0.0 \%)$ & $0(0.0 \%)$ & $12(2.9 \%)$ \\
\hline & $\mathrm{ipaH/EIEC}$ & $2(1.0 \%)$ & $3(5.8 \%)$ & $1(1.6 \%)$ & $2(2.0 \%)$ & $8(2.0 \%)$ & $0(0.0 \%)$ & $0(0.0 \%)$ & $8(7.8 \%)$ & $0(0.0 \%)$ & $0(0.0 \%)$ & $0(0.0 \%)$ & $0(0.0 \%)$ & $8(2.0 \%)$ \\
\hline & PAI IICFT073 & $21(10,2 \%)$ & $4(7.7 \%)$ & $23(37.1 \%)$ & $7(6.9 \%)$ & $55 / 13.1 \%$ & $34(20 \%)$ & $9(32.1 \%)$ & $0(0.0 \%)$ & $9(14.5 \%)$ & $0(0.0 \%)$ & $0(0.0 \%)$ & $4(14.8 \%)$ & $55 / 13.1 \%$ \\
\hline ExPEC & PAI IV536 & $84(41.0 \%)$ & $16(30.8 \%)$ & $8(13.0 \%)$ & $31(30.4 \%)$ & $139 / 33.0 \%$ & $89(52.5 \%)$ & $8(28.6)$ & $2(1.9 \%)$ & $21(33.9 \%)$ & $2(10.5 \%)$ & $4(33.3 \%)$ & $13(48.1 \%)$ & $139 / 33.0 \%$ \\
\hline
\end{tabular}

TABLE X: Distribution Of THE ESCHERICHIA COLI PHYLOGENETIC GROUPS IN THE FOUR TERTIARy HOSPITALS AND CliniCAL SPECIMENS

\begin{tabular}{|c|c|c|c|c|c|c|c|c|c|c|c|c|c|c|c|}
\hline \multirow[b]{2}{*}{$\begin{array}{l}\text { Phylogenetic } \\
\text { group (PG) }\end{array}$} & \multirow{2}{*}{$\begin{array}{l}\text { Phylogenetic } \\
\text { subgroup } \\
\text { (PSG) }\end{array}$} & \multicolumn{7}{|c|}{ Tertiary hospital } & \multicolumn{7}{|c|}{ Clinical Specimen } \\
\hline & & MNRH & MRRH & MBRRH & KIU-TH & Total & PSGP (\%) & $\begin{array}{l}\text { PGP } \\
(\%)\end{array}$ & Urine & Blood & Anal swabs & $\begin{array}{c}\text { Wound/ pus } \\
\text { swabs }\end{array}$ & Sputum & $\begin{array}{l}\text { Tracheal } \\
\text { aspirate }\end{array}$ & $\begin{array}{c}\text { Virginal } \\
\text { swabs }\end{array}$ \\
\hline & A0 & $33(16.1 \%$ & $0(0.0 \%)$ & $3(4.8 \%)$ & $18(17.7 \%)$ & 54 & 12.8 & \multirow{2}{*}{30.2} & $19(15 \%)$ & $3(2.4 \%)$ & $12(9.5 \%)$ & $9(7.1 \%)$ & $2(1.6 \%)$ & $6(4.7 \%)$ & $3(2.4 \%)$ \\
\hline A & A1 & $21(10.2 \%)$ & $18(34.6 \%)$ & $11(17.7 \%)$ & $23(22.6 \%)$ & 73 & 17.3 & & $17(13.4 \%)$ & $8(6.3 \%)$ & $11(8.7 \%)$ & $20(15.8 \%)$ & $12(9.5 \%)$ & $0(0.0 \%)$ & $5(3.9 \%)$ \\
\hline B1 & N/A & $38(18.5 \%)$ & $14(26.9 \%)$ & $17(27.4 \%)$ & $22(21.6 \%)$ & 91 & 21.6 & 21.6 & $7(7.7 \%)$ & $1(1.1)$ & $74(81.3 \%)$ & $3(3.3 \%)$ & $3(3.3 \%)$ & $1(1.1 \%)$ & $2(2.2 \%)$ \\
\hline \multirow{2}{*}{ B2 } & B22 & $6(1.0 \%)$ & $2(3.9 \%)$ & $4(6.5 \%)$ & $3(2.9 \%)$ & 15 & 3.7 & \multirow{2}{*}{41.1} & $11(6.4 \%)$ & $0(0.0 \%)$ & $1(0.6 \%)$ & $3(1.7 \%)$ & $0(0.0 \%)$ & $0(0.0 \%)$ & $0(0.0 \%)$ \\
\hline & B23 & $92(44.9 \%)$ & $18(34.6 \%)$ & $21(33.9 \%)$ & $27(26.5 \%)$ & 158 & 37.5 & & $94(54.3 \%)$ & $13(7.5 \%)$ & $3(1.7 \%)$ & $24(13.9 \%)$ & $2(1.2 \%)$ & $5(2.9 \%)$ & $17((.8 \%)$ \\
\hline \multirow[b]{2}{*}{$\mathrm{D}$} & D1 & $5(2.4 \%)$ & 0. $(0.0 \%)$ & $0(0.0 \%)$ & $3(2.9 \%)$ & 8 & 1.9 & \multirow{2}{*}{7.1} & $6(20.0 \%)$ & $0(0.0 \%)$ & $2(6.7 \%)$ & $0(0.0 \%)$ & $0(0.0 \%)$ & $0(0.0 \%)$ & $0(0.0 \%)$ \\
\hline & D2 & $10(4.9 \%)$ & $0(0.0 \%)$ & $6(9.7 \%)$ & $6(5.9 \%)$ & 22 & 5.2 & & $16(53.3 \%)$ & $3(10 \%)$ & $0(0.0 \%)$ & $3(10 \%)$ & $0(0.0 \%)$ & $0(0.0 \%)$ & $0(0.0 \%)$ \\
\hline Total & & 205 & 52 & 62 & 102 & 421 & 100 & 100 & 170 & 28 & 103 & 62 & 19 & 12 & 27 \\
\hline
\end{tabular}




\section{F. Dispersion of Pathogenic E. coli in Tertiary Hospitals and Clinical Specimens}

\section{Diarrheagenic Escherichia coli (DEC)}

Out of 421 MDR E. coli isolates, 19.7\% (83/421) harboured virulence genetic determinants. MBRRH had the highest prevalence of DEC $(17 / 62=27.4 \%)$ followed by MBRH $\quad(12 / 52=23.1 \%)$, KIU-TH $\quad(21 / 102=20.6 \%)$ and MNRH $(35 / 205=17.1 \%)$. However, the DEC prevalence was not statistically different among hospitals. Among the DEC detected, EPEC pathotype recorded significantly higher prevalence of $10.8 \%$ followed by S-ETEC (3.1\%), STEC (2.9\%), EIEC (2.0\%) and L-ETEC (2.0\%). Pathotypes EAEC and ESHEC were not detected in this study, thus scored a prevalence of $0 \%$. Among clinical specimens, DEC were predominantly isolated from anal swabs $(75 / 83=90.4 \%)$ followed by urine $(4 / 83=4.8 \%)$, sputum $(2 / 83)$ blood $(1 / 83)$ and wound/pus swabs (1/83) (Table IX).

\section{Extraintestinal Pathogenic Escherichia coli (ExPEC)}

Multiplex PCR amplification targeting the pathogenicity islands (PAIs) was used detect ExPEC, Fig. 1. The overall prevalence of ExPEC was 46.1\% (194/421). E. coli isolates possessing PAIs were predominantly obtained from MNRH $(105 / 205=54.2 \% / 105)$, trailed by MBRRH $(31 / 62=50.0 \%)$, MRRH $(20 / 52=38.5 \%)$ and then KIU-TH $(38 / 102=37.3 \%)$. PAI IV $_{536}$ was the most predominant chromosomal region detected $(33.0 \%)$ and then PAI II CFT073 $_{3}(13.1 \%)$. Furthermore, 20 isolates had both PAI IV 536 and PAI II $_{\text {CFT073. PAI I }}$ 536, PAI

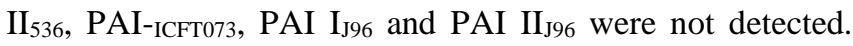
Urine samples registered the highest prevalence of ExPEC. Of the 170 isolates obtained from urine, $72.5 \%$ (123) were ExPEC followed by virginal swabs $(17 / 27=62.9 \%)$, blood $(17 / 28=60.7 \%)$, wound/pus swabs $(30 / 62=48.4 \%)$, Tracheal aspirate $(4 / 12=33.3 \%)$, sputum $(2 / 19=10.5 \%)$ and anal swabs $(2 / 103=1.9 \%)$. The prevalence of ExPEC in urine, virginal swabs, blood, wound/pus swabs was substantially higher than ExPEC prevalence obtained from tracheal aspirate, sputum and anal swabs (Table IX).

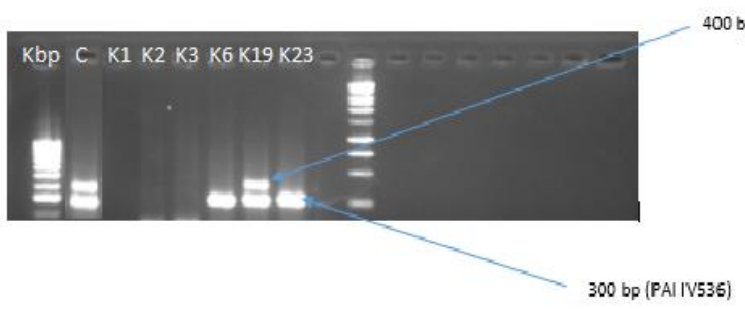

Fig. 1. PCR amplification of pathogenic islands; Kbp: 2 Kilo base pair ladder, C: Control, K: Kampala International University-Teaching hospital isolates.

\section{G. Distribution of the Escherichia coli Phylogenetic Groups}

E. coli (421) isolated from several clinical specimens were characterized into four phylogenetic groups (PG) and six phylogenetic subgroups based on the triplex PCR, Fig. 2. E. coli belonging to phylogenetic group B2 was predominantly detected and scored a prevalence of $41.1 \%$. This was trailed by phylogenetic group A $(30.2 \%)$, phylogenetic group B1 $(21.6 \%)$ and phylogenetic group D (7.1\%). E. coli belonging to Phylogenetic group A, B2 and D were majorly isolated from urine samples whereas phylogenetic group B1 isolates were mainly obtained from anal swabs (Table X).

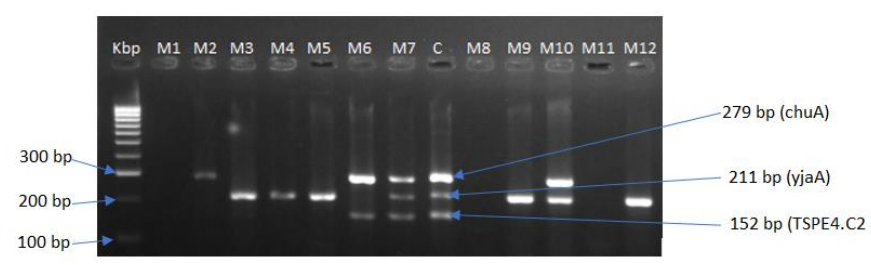

Fig. 2. Triplex amplification of the chuA, yjaA and TSPE4.C2 genes; Kbp: Kilo base pair DNA ladder, M: Mulago National Referral Hospital isolates and $\mathrm{C}$ : control.

\section{H. Virulence Genes and Carbapenem Resistance Profiles among the Phylogenetic Groups}

EIEC (ipaH gene) was detected in one carbapenem susceptible $E$. coli isolate belonging to phylogenetic group A. PAI II $_{\text {CFT073 }}$ and PAI IV $_{536}$ were also detected in one carbapenem susceptible and two carbapenem resistant phylogenetic group A isolates respectively. Out of the 83 DEC, $98.8 \%$ (82) resided within phylogenetic group B1 and $38.6 \%$ (32) expressed phenotypic carbapenem resistance. Furthermore, $86.1 \%$ (120 PAI IV 536 and 47 PAI II CFT073 of the ExPEC were characterized as phylogenetic group B2 of which $21 \%$ (41) were resistant to carbapenems. Phylogenetic group D contained 12.4\% ExPEC (17 PAI IV 536 and 07 PAI $\mathrm{II}_{\mathrm{CFT} 073}$ ) and $2.1 \%$ (4) of the phylogenetic group D ExPEC were resistant (Table XI).

TABLE XI: Distribution of PATHOGENIC GENES AMONG THE ESCHERICHIA COLI PHYLOGENETIC GROUPS AND THEIR CARBAPENEM RESISTANCE PROFILES

\begin{tabular}{|c|c|c|c|c|c|c|c|c|c|c|c|c|c|c|c|}
\hline \multirow[t]{3}{*}{ PG } & \multirow[t]{3}{*}{ PSG } & \multicolumn{10}{|c|}{ Virulent genes found in DEC pathotypes } & \multicolumn{4}{|c|}{$\begin{array}{c}\text { Pathogenicity Islands that harbor } \\
\text { virulent genes in ExPEC }\end{array}$} \\
\hline & & \multicolumn{2}{|c|}{ eae } & \multicolumn{2}{|c|}{ elt } & \multicolumn{2}{|c|}{ ipaH } & \multicolumn{2}{|c|}{ sxt } & \multicolumn{2}{|c|}{ est } & \multicolumn{2}{|c|}{ PAI IICFT073 } & \multicolumn{2}{|c|}{ PAI IV536 } \\
\hline & & $\mathrm{R}$ & $\mathrm{S}$ & $\mathrm{R}$ & $\mathrm{S}$ & $\mathrm{R}$ & $\mathrm{S}$ & $\mathrm{R}$ & $\mathrm{S}$ & $\mathrm{R}$ & $\mathrm{S}$ & $\mathrm{R}$ & $\mathrm{S}$ & $\mathrm{R}$ & $\mathrm{S}$ \\
\hline \multirow[t]{2}{*}{ A } & A0 & 0 & 0 & 0 & 0 & 0 & 1 & 0 & 0 & 0 & 0 & 0 & 0 & 0 & 0 \\
\hline & A1 & 0 & 0 & 0 & 0 & 0 & 0 & 0 & 0 & 0 & 0 & 0 & 1 & 2 & 0 \\
\hline B1 & B1 & 19 & 23 & 4 & 4 & 3 & 4 & 3 & 9 & 3 & 10 & 0 & 0 & 0 & 0 \\
\hline \multirow[t]{2}{*}{ B2 } & B22 & 0 & 0 & 0 & 0 & 0 & 0 & 0 & 0 & 0 & 0 & 2 & 1 & 4 & 6 \\
\hline & B23 & 0 & 0 & 0 & 0 & 0 & 0 & 0 & 0 & 0 & 0 & 15 & 29 & 20 & 90 \\
\hline \multirow[t]{2}{*}{ D } & D1 & 0 & 0 & 0 & 0 & 0 & 0 & 0 & 0 & 0 & 0 & 1 & 5 & 0 & 2 \\
\hline & D2 & 0 & 0 & 0 & 0 & 0 & 0 & 0 & 0 & 0 & 0 & 0 & 1 & 3 & 12 \\
\hline Total & & \multicolumn{2}{|c|}{42} & \multicolumn{2}{|c|}{8} & \multicolumn{2}{|c|}{8} & \multicolumn{2}{|c|}{12} & \multicolumn{2}{|c|}{13} & \multicolumn{2}{|c|}{55} & \multicolumn{2}{|c|}{139} \\
\hline
\end{tabular}

PG: Phylogenetic group, PSG: Phylogenetic subgroup. 


\section{DISCUSSION}

Despite the fact that $E$. coli is the leading cause of urinary tract infections and diarrheal infection worldwide, to the best of our knowledge, this is the first study from the East African region to investigate the carbapenem resistance profile, virulence pattern and phylogenetic groups among MDR $E$. coli clinical isolates. Knowledge of the prevalence of pathogenic E. coli and their antimicrobial resistance pattern is vital in the designing of strategies to control the spread of such superbugs.

Findings of this study revealed that the overall phenotypic carbapenem resistance prevalence stood at $22.8 \%$. Comparable results were achieved by previous studies in Low Middle Income countries (LMIC) with similar healthcare systems. For example, prevalence of carbapenem resistance in Tanzania was 24\% [29], Nigeria $15.2 \%, 27.4 \%$ and $36.8 \%$ ) [30-32], India $31.77 \%$ [33]. Contrary, this frequency is higher than carbapenem resistance levels reported in countries like Ghana (7.2\%) [34], Morocco 5.99\% [35], and Ethiopia $2.73 \%$, [36] with similar healthcare settings but lower than the incidences above 50\% reported in South Africa, Egypt and Tunisia [37-41].

Multiplex PCR screening identified carbapenemase encoding genes in $33.0 \%$ of the isolates. This genotypic carbapenem resistance prevalence corroborates with earlier studies conducted in the East African region [29, 42, 43] and elsewhere $[31,44]$ that reported levels ranging from $25 \%$ to $40 \%$. Contrary, this frequency is significantly lower than carbapenem genotypic levels reported by studies in Tunisia (76.7\%) [45], South Africa (68\% and 86\%) [37, 38], Egypt $(89.6 \%)$ [41], Turkey (49.5\%) [46]. KPC, VIM, NDM, OXA48 and IMP are the commonest carbapenemases worldwide [47]. Findings of this study revealed the existence of all those carbapenemases encoding genes in Uganda and OXA-48 was the most predominant gene in contrast with previous studies in the region $[29,42]$ but in agreement with recent studies in carried out in Africa [35, 37, 40, 45]. OXA-48 carbapenemase was first detected in Turkey and it became epidemic in the Middle East and Mediterranean countries [46]. This indicates that OXA-48 habouring Enterobacteriaceae have spread widely in sub-Saharan Africa to become too most prevalent.

This study found considerable variation between phenotypic and genotypic resistance. Among the E. coli isolates that harboured blaVIM gene, $97.3 \%$ exhibited phenotypic resistance while for blaOXA-48, only $37.9 \%$ expressed phenotypic resistance. It is important noting that four isolates coharboured more than one gene each but susceptible to carbapenems. Carbapenemases expressed by OXA-48 and its variant genes possess low carbapenems hydrolyzing activity [48-50]. This provided an insight into why $62.1 \%$ of the isolates which possessed OXA-48-like genes did not exhibit phenotypic resistance. Alteration and reduced expression of the outer membrane proteins that act as drug channels complement enzymes expressed by the resistant genes and this mechanism is highly effective against Ertapenem [50, 51]. Thus, carbapenem resistance is not exclusively due to expression carbapenemases. This explains why not all the isolates that harbored carbapenemase genes were carbapenem insusceptible and why resistance to ertapenem was significantly higher. Despite of absence of carbapenem resistance genes, a total of eight sample displayed phenotypic resistance. Thus, resistance in these isolates may be attributed to (a) a combination of loss of outer membrane proteins (OMPs), (OmpK35 and OmpK36) and overexpression of extended spectrum beta-lactamasesESBLs (CTX-Ms or SHV-2) or plasmid-borne AmpC enzymes (ACT-1, CMY-2, CMY-4 or DHA-1) [52, 53] and (b) presence of other carbapenemase such as Guiana extended Spectrum enzyme / integron-borne cephalosporinase (GES/IBC), Serratia marcescens enzyme ( $\left.\mathrm{SME}_{1-3}\right)$, Not Metalloenzyme carbapenemase (NMC-A ), Imipenemhydrolyzing beta lactamase (IMI), Sao Paulo metallolactamase (SPM), German imipenemase (GIM), Seoul imipenemase (SIM) and Kyorin University Hospital metallolavtamase (KHM) [54].

Enterohemorrhaghic E. coli (EHEC), enteropathogenic Escherichia coli (EPEC), enterotoxigenic E. coli (ETEC), enteroinvasive E. coli (EIEC), enteroaggregative E. coli (EAEC) and diffusely adherent E. coli (DAEC) have been reported as the main causes of diarrheal disease in several parts of Africa, predominantly among young children [55]. This study revealed high prevalence of diarrheagenic MDR E. coli clinical isolates obtained from different tertiary hospitals as $19.7 \%(83 / 421)$ of the isolates harboured virulence genetic determinant. Of the 83 DEC pathotypes, EPEC was the most encountered (51.0\%) followed by SETEC, STEC and EIEC and L-ETCE. This correlates well with studies conducted outside the African content [56, 57]. In contrast, similar studies carried out in sub-Saharan Africa (Tanzania, South Africa and Mozambique) reported EAEC as the most prevalent DEC pathotype [58-62] yet it was not detected in this study. As expected, DEC were predominantly isolated from Anal/fecal swabs. However, 9.6\% (8/83) were obtained from other clinical specimens. Indeed, several have isolated DEC pathotypes from other clinical specimens other than stool and have been implicated as some of the causes of hemolytic uremic syndrome [63, 64].

In this study, multiplex PCR was used to target pathogenicity Islands (PAI). PAIs harbour virulence genes in ExPEC that are responsible for pathogenicity [65-67]. The overall prevalence of ExPEC as revealed by molecular typing of PAI in our study was $46.1 \%$ (194/421). Of the two PAIs detected, PAI IV536 also known as high pathogenicity Island (HPI) was substantially dominant with a genotypic frequency of $71.7 \%$ and PAI IICFT073 had a frequency of $28.3 \%$. This is in agreement with previous studies $[22,65]$ which reported PAI IV536 as the most prevalent PAI. The main virulence genes residing in the PAI IV536 and PAI IICFT073 are yersiniabactin siderophore iron-uptake system and $\mathrm{P}$. fimbriae as well as iron regulated proteins respectively [66, $68,69]$. A previous study in Uganda reported high prevalence of $E$. coli with P. fimbriae virulent factor encoded for by the pap gene in UPEC [70]indicating high prevalence of PAI IICFT073 pathotypes. However, this study never attempted to detect genes encoding the yersiniabactin siderophore ironuptake system in PAI IV536 UPEC; thus, there is no available data about the prevalence of PAI IV536 for comparison purposes. As anticipated, ExPEC that harboured PAIs were majorly isolated from urine and virginal swabs. However, a total of 55 isolates obtained from blood (17), wound/pus swabs (30), tracheal aspirate (4) anal swabs (2) and sputum 
(2) harboured PAIs. PAI IJ96 E. coli have been reported to be both UPEC and NMNEC [71] but this study did not detect any PAI IJ96. Thus, all the E. coli isolates that possessed PAI $\mathrm{IV}_{536}$ and PAI II $\mathrm{IFT}_{\mathrm{CF} 3}$ were deemed to be UPEC.

Phylogenetic analysis revealed that E. coli isolates obtained from the four tertiary hospitals located in the Central region (MNRH), Western region (MBRRH), South Western Region (KIU-TH) and Eastern Region (MRRH) belonged to the phylogroups A B1, B2 and D and phylogenetic sub groups A0, A1, B22, B23, D1 and D2. Pathogenic intestinal E. coli (DEC) mainly belong to Phylogenetic groups A, B1, and D, commensals to the groups A and B1, and strains usually belong to the groups B2 and D [13, 14]. In our study, phylogenetic analysis predominantly clustered $E$. coli clinical isolates into $\mathrm{B} 2$ followed by $\mathrm{A}, \mathrm{B} 1$ and $\mathrm{D}$ and this corroborates with findings from previous studies [72, 73]. However, contradicting results have been reported worldwide where A is the most abundantly isolated phylogroup [74-77]. Distribution of $E$. coli phylogroups among different ecological zones is influenced by environment factor; thus, this accounts for variability in prevalence of the phylogenetic groups in different countries [78]. In this study, statistically similar (P value 0.9998) distribution of phylogenetic groups A, B1, B2 and D among regions was observed. This pattern of distributes indicates inter-region transmission of UPEC, DEC and commensals. It was observed that phylogenetic group A, B2 and D strains were majorly isolated from urine and this is in affirmative with all studies that conducted phylogenetic analysis of E. coli clinical isolates [79-81] whereas B1 strains were predominantly isolated from anal/fecal swabs, this does not corroborate with previous studies which found phylogroup A strains as the most dominant fecal isolates [76, 77, 82].

World over, an increase in pathogenic and commensal $E$. coli strains harbouring antibiotic resistance determinants has been observed. The situation has been complicated by acquisition of antibiotic resistance by other Enterobacteriaceae as several studies have reported that infections caused by resistant bacteria are hard to treat, lead to increase in treatment costs, morbidity and mortality [83]. Antibiotic resistance in Enterobacteriaceae is mainly mediated by beta-lactamase enzymes that inactivate betalactam antibiotics by hydrolyzing the peptide bond of the beta-lactam ring. Among the beta-lactamases, carbapenemases are the most important because acquisition of carbapenem resistance genes confer resistance to all beta lactam antibiotics. Furthermore, carbapenem are the most suitable choice antibiotics for treatment of MDR GramNegative bacterial infections; [48] thus, infection with carbapenem resistant bacteria significantly prolong the period of stay in hospital and responsible for $10 \%$ mortality [84]. Thus, in this study we assessed the carriage of carbapenem resistance and virulence genetic factors among $E$. coli phylogroups. We observed that among the 83 isolates that harboured virulence genetic determinants for DEC, $98.8 \%$ (82) and $1.2 \%$ (1) belonged to phylogenetic group B1 and A respectively and $38.6 \%$ (32) expressed phenotypic resistance. Whereas $86.1 \%$ (167), $12.4 \%$ (24) and $1.6 \%$ (3) of the isolates that had PAIs were characterized as phylogroups B2, D and A respectively and $24.1 \%$ (47) were carbapenem resistant. Coexistence of virulence factors and carbapenem resistance was observed in $18.8 \%(79 / 421)$ of the total isolates. Our findings show that carbapenemases production was significantly higher in $\mathrm{B} 1$ and $\mathrm{B} 2(\mathrm{P}<0.0001)$. This is extremely scaring as DEC and ExPEC mainly fall under phylogenetic groups B1 and B2 respectively. Furthermore, existence of virulence genes and genetic determinants of resistance in phylogenetic groups $\mathrm{A}$ and $\mathrm{D}$ where commensal mainly fall should be treated as a major threat as they are considered to reservoirs of genetic determinants of virulence and antibiotic resistance and they donate these traits to the pathogenic strains of phylogroups B1 and B2 through horizontal gene transfer, arbitrated regularly by plasmids and transposons [49]. Indeed, previous studies observed that PAIs are mobile genetic elements (transposons) that are transferred from one E. coli strain to another through horizontal gene transfer mediated by bacteriophages, conjugative plasmids, conjugation and homologous DNA recombination $[69,85$, 86].

\section{CONCLUSION}

Our data indicate high level of carriage of carbapenem resistance among the DEC and ExPEC clinical isolates belonging to phylogenetic group B1 and B2 respectively. DEC and ExPEC pathogenicity and antimicrobial resistance are mediated by genetic factors such as chromosomal/plasmid borne virulence and antibiotic resistance genes as well as chromosomal PAIs virulent genes. Plasmid and PAIs are mobile genetic elements that facilitate horizontal gene transfer contributing to plasticity of the genome. In light of this, routine genetic analysis of $E$. coli clinical and environment isolates is important to better understand the level of pathogenicity and antimicrobial as this will inform the possible burden such isolates are likely to pose to the healthcare system.

\section{ACKNOWLEDGEMENTS}

We are thankful to the Africa Centre of Excellence in Materials, Product Development \& Nanotechnology; MAPRONANO ACE, Grant No. P151847IDA credit $5797-$ UG, College of Engineering Design Art and Technology, Makerere University and WHO-TDR, grant No. 2020/1037452-0 for funding this study.

\section{REFERENCES}

[1] Ali, M.M.M., et al., Molecular characterization of diarrheagenic Escherichia coli from Libya. J The American journal of tropical medicine hygiene, 2012. 86(5): p. 866-871.

[2] Sader, H.S., et al., Four-year evaluation of frequency of occurrence and antimicrobial susceptibility patterns of bacteria from bloodstream infections in Latin American medical centers. J Diagnostic microbiology infectious disease, 2002. 44(3): p. 273-280.

[3] Kaper, J.B., J.P. Nataro, and H.L. Mobley, Pathogenic escherichia coli. J Nature reviews microbiology, 2004. 2(2): p. 123-140.

[4] Russo, T.A. and J.R. Johnson, Proposal for a new inclusive designation for extraintestinal pathogenic isolates of Escherichia coli: ExPEC. J The Journal of infectious diseases, 2000. 181(5): p. 1753-1754.

[5] Smith, J.L., et al., Extraintestinal pathogenic Escherichia coli. 2007. 4(2): p. 134-163.

[6] Aranda, K.R., et al., Single multiplex assay to identify simultaneously enteropathogenic, enteroaggregative, enterotoxigenic, enteroinvasive 
and Shiga toxin-producing Escherichia coli strains in Brazilian children. 2007. 267(2): p. 145-150.

[7] Brandal, L.T., et al., Octaplex PCR and fluorescence-based capillary electrophoresis for identification of human diarrheagenic Escherichia coli and Shigella spp. 2007. 68(2): p. 331-341.

[8] Diamant, E., et al., Phylogeny and strain typing of Escherichia coli, inferred from variation at mononucleotide repeat loci. 2004. 70(4): p. 2464-2473.

[9] Clements, A., et al., Infection strategies of enteric pathogenic Escherichia coli. 2012. 3(2): p. 71-87.

[10] Johnson, J.R. and A.L. Stell, Extended virulence genotypes of Escherichia coli strains from patients with urosepsis in relation to phylogeny and host compromise. J The Journal of infectious diseases, 2000. 181(1): p. 261-272.

[11] Johnson, T.J., et al., Identification of minimal predictors of avian pathogenic Escherichia coli virulence for use as a rapid diagnostic tool. Journal of clinical microbiology, 2008. 46(12): p. 3987-3996.

[12] Le Bouguenec, C., M. Archambaud, and A. Labigne, Rapid and specific detection of the pap, afa, and sfa adhesin-encoding operons in uropathogenic Escherichia coli strains by polymerase chain reaction. $\mathrm{J}$ Journal of clinical microbiology, 1992. 30(5): p. 1189-1193.

[13] Clermont, O., S. Bonacorsi, and E. Bingen, Rapid and simple determination of theEscherichia coli phylogenetic group. Applied environmental microbiology, 2000. 66(10): p. 4555-4558.

[14] Barzan, M., D. Gharibi, and M. Ghorbanpoor, Phylogenetic grouping and phenotypic detection of extended-spectrum $\beta$-lactamases among Escherichia coli from calves and dairy cows in Khuzestan, Iran. Haji, Hajikolaei Mohammad Rahim Pourmehdi, Boroujeni Mehdi 2017.

[15] Ssekatawa, K., et al., Prevalence of pathogenic Klebsiella pneumoniae based on PCR capsular typing harbouring carbapenemases encoding genes in Uganda tertiary hospitals. Antimicrobial Resistance \& Infection Control, 2021. 10(1): p. 57.

[16] Ssekatawa, K., et al., A systematic review: the current status of carbapenem resistance in East Africa. BMC Res Notes, 2018. 11(1): p. 629.

[17] CLSI., Performance Standards for Antimicrobial Disk Susceptibility Tests for Bacteria Isolated from Animals: CLSI Supplement VET01SEd5E; Replaces VET01-S2. 2020: Clinical and Laboratory Standards Institute.

[18] Dallenne, C., et al., Development of a set of multiplex PCR assays for the detection of genes encoding important $\beta$-lactamases in Enterobacteriaceae. 2010. 65(3): p. 490-495.

[19] Fischer, J., et al., Escherichia coli producing VIM-1 carbapenemase isolated on a pig farm. 2012. 67(7): p. 1793-1795.

[20] Ochman, H. and R.K. Selander, Standard reference strains of Escherichia coli from natural populations. J Journal of bacteriology, 1984. 157(2): p. 690-693.

[21] Toma, C., et al., Multiplex PCR assay for identification of human diarrheagenic Escherichia coli. 2003. 41(6): p. 2669-2671.

[22] Sabaté, M., et al., Pathogenicity island markers in commensal and uropathogenic Escherichia coli isolates. 2006. 12(9): p. 880-886.

[23] Dias, M.T., et al., Molecular characterization and evaluation of antimicrobial susceptibility of enteropathogenic E. coli (EPEC) isolated from minas soft cheese. J Food Science Technology, 2012. 32(4): p. 747 753.

[24] Oswald, E., et al., Typing of intimin genes in human and animal enterohemorrhagic and enteropathogenic Escherichia coli: characterization of a new intimin variant. 2000. 68(1): p. 64-71.

[25] Yamasaki, S., et al., Typing of verotoxins by DNA colony hybridization with poly-and oligonucleotide probes, a bead-enzyme-linked immunosorbent assay, and polymerase chain reaction. 1996. 40(5): p. 345-352.

[26] López-Saucedo, C., et al., Single multiplex polymerase chain reaction to detect diverse loci associated with diarrheagenic Escherichia coli. 2003. 9(1): p. 127.

[27] Sethabutr, O., et al., Detection of Shigellae and enteroinvasive Escherichia coli by amplification of the invasion plasmid antigen $H$ DNA sequence in patients with dysentery. 1993. 167(2): p. 458-461.

[28] Ratchtrachenchai, O.-A., S. Subpasu, and K. Ito, Investigation on enteroaggregative Escherichia coli infection by multiplex PCR. J Bull. Dept. Med. Sci, 1997. 39(4): p. 211-220.

[29] Mushi, M.F., et al., Carbapenemase genes among multidrug resistant gram negative clinical isolates from a tertiary hospital in Mwanza, Tanzania. 2014. 2014.

[30] Ogbolu, D. and M. Webber, High-level and novel mechanisms of carbapenem resistance in Gram-negative bacteria from tertiary hospitals in Nigeria. J International journal of antimicrobial agents, 2014. 43(5): p. 412-417.

[31] Olalekan, A., et al., High proportion of carbapenemase-producing Escherichia coli and Klebsiella pneumoniae among extended-spectrum
B-lactamase-producers in Nigerian hospitals. J Glob Antimicrob Resist, 2020. 21: p. 8-12.

[32] Oduyebo, O.O., et al., Phenotypic determination of carbapenemase producing enterobacteriaceae isolates from clinical specimens at a tertiary hospital in Lagos, Nigeria. Niger Postgrad Med J, 2015. 22(4): p. 223-7.

[33] Pawar, S.K., et al., Carbapenem-resistant Enterobacteriaceae: Prevalence and bacteriological profile in a tertiary teaching hospital from rural western India. 2018. 5(3): p. 342-347.

[34] Hackman, H.K., et al., Emergence of Carbapenem-resistant Enterobacteriaceae among Extended-spectrum Beta-lactamase Producers in Accra, Ghana. 2017. 7(24).

[35] Mahrach, Y., et al., Phenotypic and molecular study of carbapenemaseproducing Enterobacteriaceae in a regional hospital in northern Morocco. 2019. 3: p. 113.

[36] Eshetie, S., et al., Multidrug resistant and carbapenemase producing Enterobacteriaceae among patients with urinary tract infection at referral Hospital, Northwest Ethiopia. Antimicrobial Resistance and Infection Control, 2015. 4(1): p. 12.

[37] Perovic, O., et al., Carbapenem-resistant Enterobacteriaceae in patients with bacteraemia at tertiary hospitals in South Africa, 2015 to 2018 European Journal of Clinical Microbiology \& Infectious Diseases, 2020. 39(7): p. 1287-1294.

[38] Singh-Moodley, A. and O. Perovic, Antimicrobial susceptibility testing in predicting the presence of carbapenemase genes in Enterobacteriaceae in South Africa. \%J BMC infectious diseases, 2016. 16(1): p. 536.

[39] Kotb, S., et al., Epidemiology of carbapenem-resistant Enterobacteriaceae in Egyptian intensive care units using National Healthcare-associated Infections Surveillance Data, 2011-2017. 2020. 9(1): p. 1-9.

[40] ElMahallawy, H.A., et al., Spread of carbapenem resistant Enterobacteriaceae at tertiary care cancer hospital in Egypt. 2018. 50(7): p. 560-564.

[41] Tawfick, M.M., et al., The emergence of carbapenemase blaNDM genotype among carbapenem-resistant Enterobacteriaceae isolates from Egyptian cancer patients. European Journal of Clinical Microbiology \& Infectious Diseases, 2020. 39(7): p. 1251-1259.

[42] Okoche, D., et al., Prevalence and characterization of carbapenemresistant Enterobacteriaceae isolated from Mulago National Referral Hospital, Uganda. 2015. 10(8): p. e0135745.

[43] Ampaire, L.M., et al., Epidemiology of carbapenem resistance among multi-drug resistant enterobacteriaceae in Uganda. 2015. 8(2): p. 418.

[44] Mahmoud, N.E., H.N. Altayb, and R.M. Gurashi, Detection of Carbapenem-Resistant Genes in Escherichia coli Isolated from Drinking Water in Khartoum, Sudan. Journal of Environmental and Public Health, 2020. 2020: p. 2571293.

[45] Kollenda, H., et al., Screening for carbapenemases in ertapenemresistant Enterobacteriaceae collected at a Tunisian hospital between 2014 and 2018. 2019. 9(1): p. 9-13.

[46] Baran, I. and N. Aksu, Phenotypic and genotypic characteristics of carbapenem-resistant Enterobacteriaceae in a tertiary-level reference hospital in Turkey. J Annals of clinical microbiology antimicrobials, 2016. 15(1): p. 20.

[47] Demir, Y., Y. Zer, and I. Karaoglan, Investigation of VIM, IMP, NDM1, KPC AND OXA-48 enzymes in Enterobacteriaceae strains. J Pakistan journal of pharmaceutical sciences, 2015. 28.

[48] Nordmann, P., L. Dortet, and L. Poirel, Carbapenem resistance in Enterobacteriaceae: here is the storm! J Trends in molecular medicine, 2012. 18(5): p. 263-272.

[49] Nordmann, P., T. Naas, and L. Poirel, Global spread of Carbapenemaseproducing Enterobacteriaceae. Emerg Infect Dis, 2011. 17(10): p. 1791 8.

[50] Codjoe, F.S. and E.S. Donkor, Carbapenem Resistance: A Review. Med Sci (Basel), 2017. 6(1).

[51] Bou, G., et al., Characterization of a nosocomial outbreak caused by a multiresistant Acinetobacter baumannii strain with a carbapenemhydrolyzing enzyme: high-level carbapenem resistance in A. baumannii is not due solely to the presence of beta-lactamases. J Clin Microbiol, 2000. 38(9): p. 3299-305.

[52] Crowley, B., V. Benedí, and A. Doménech-Sánchez, Expression of SHV2 beta-lactamase and of reduced amounts of OmpK36 porin in Klebsiella pneumoniae results in increased resistance to cephalosporins and carbapenems. Antimicrob Agents Chemother, 2002. 46(11): p 3679-82.

[53] Yang, D., Y. Guo, and Z. Zhang, Combined porin loss and extended spectrum $\beta$-lactamase production is associated with an increasing imipenem minimal inhibitory concentration in clinical Klebsiella pneumoniae strains. J Current microbiology, 2009. 58(4): p. 366. 
[54] Queenan, A. and K. Bush, Carbapenemases: the versatile betalactamases. Clin Microbiol Rev, 2007. 20(3): p. 440-58, table of contents.

[55] Okeke, I.N., Diarrheagenic Escherichia coli in sub-Saharan Africa: status, uncertainties and necessities. J The journal of infection in developing countries, 2009. 3(11): p. 817-842.

[56] Keskimäki, M., et al., Prevalence of diarrheagenic Escherichia coli in finns with or without diarrhea during a round-the-world trip. J Clin Microbiol, 2000. 38(12): p. 4425-9.

[57] Zhou, Y., et al., Characteristics of diarrheagenic Escherichia coli among children under 5 years of age with acute diarrhea: a hospital based study. 2018. 18(1): p. 63.

[58] Mandomando, I.M., et al., Etiology of diarrhea in children younger than 5 years of age admitted in a rural hospital of southern Mozambique. Am J Trop Med Hyg, 2007. 76(3): p. 522-7.

[59] Aijuka, M., et al., Enteroaggregative Escherichia coli is the predominant diarrheagenic E. coli pathotype among irrigation water and food sources in South Africa. Int J Food Microbiol, 2018. 278: p. 44-51.

[60] Tanih, N., et al., Prevalence of diarrheagenic Escherichia coli in young children from rural South Africa: The Mal-ED cohort. 2014. 21: p. 149.

[61] Moyo, S.J., et al., Identification of diarrheagenic Escherichia coli isolated from infants and children in Dar es Salaam, Tanzania. BMC Infectious Diseases, 2007. 7(1): p. 92.

[62] Bisi-Johnson, M.A., et al., Molecular basis of virulence in clinical isolates of Escherichia coli and Salmonella species from a tertiary hospital in the Eastern Cape, South Africa. 2011. 3(1): p. 9.

[63] Nataro, J.P. and J.B. Kaper, Diarrheagenic Escherichia coli. Clin Microbiol Rev, 1998. 11(1): p. 142-201.

[64] Herzog, K., et al., Diarrheagenic enteroaggregative Escherichia coli causing urinary tract infection and bacteremia leading to sepsis. Infection, 2014. 42(2): p. 441-444.

[65] Tangi, S.C., et al., Prevalence of pathogenicity island markers genes in uropathogenic Escherichia coli isolated from patients with urinary tract infectious. Asian Pacific Journal of Tropical Disease, 2015. 5(8): p. 662666.

[66] Middendorf, B., et al., The Pathogenicity Islands (PAIs) of the Uropathogenic Escherichia coli Strain 536: Island Probing of PAI II536. The Journal of Infectious Diseases, 2001. 183(Supplement_1): p. S17-S20.

[67] Parham, N.J., et al., Prevalence of pathogenicity island IICFT073 genes among extraintestinal clinical isolates of Escherichia coli. J Clin Microbiol, 2005. 43(5): p. 2425-34.

[68] Sarowska, J., et al., Virulence factors, prevalence and potential transmission of extraintestinal pathogenic Escherichia coli isolated from different sources: recent reports. Gut Pathogens, 2019. 11(1): p. 10 .

[69] Desvaux, M., et al., Pathogenicity Factors of Genomic Islands in Intestinal and Extraintestinal Escherichia coli. 2020. 11(2065).

[70] Katongole, P., et al., Biofilm formation, antimicrobial susceptibility and virulence genes of Uropathogenic Escherichia coli isolated from clinical isolates in Uganda. BMC Infectious Diseases, 2020. 20(1): p. 453.

[71] Schmidt, H. and M. Hensel, Pathogenicity islands in bacterial pathogenesis. Clin Microbiol Rev, 2004. 17(1): p. 14-56.

[72] Iranpour, D., et al., Phylogenetic Groups of Escherichia coli Strains from Patients with Urinary Tract Infection in Iran Based on the New Clermont Phylotyping Method. BioMed Research International, 2015. 2015: p. 846219.

[73] Ahumada-Santos, Y.P., et al., Association of phylogenetic distribution and presence of integrons with multidrug resistance in Escherichia coli clinical isolates from children with diarrhoea. Journal of Infection and Public Health, 2020. 13(5): p. 767-772.

[74] Stoppe, N.C., et al., Worldwide Phylogenetic Group Patterns of Escherichia coli from Commensal Human and Wastewater Treatment Plant Isolates. Front Microbiol, 2017. 8: p. 2512.

[75] Duriez, P., et al., Commensal Escherichia coli isolates are phylogenetically distributed among geographically distinct human populations. Microbiology (Reading), 2001. 147(Pt 6): p. 1671-1676.

[76] Li, B., et al., Phylogenetic Groups and Pathogenicity Island Markers in Fecal <em>Escherichia coli</em> Isolates from Asymptomatic Humans in China. 2010. 76(19): p. 6698-6700.

[77] Al-Mayahie, S.M., et al., Phylogenetic grouping of dominant fecal escherichia coli isolates from healthy males and females in Al-Kut/Wasit Province. 2015. 6.

[78] Escobar-Pa'ramo, P., et al., Large-scale population structure of human commensal Escherichia coli isolates. Appl. Environ. Microbiol. 70:5698-5700., 2004.

[79] Lee, J.H., et al., Phylogenetic group distributions, virulence factors and antimicrobial resistance properties of uropathogenic Escherichia coli strains isolated from patients with urinary tract infections in South Korea. 2016. 62(1): p. 84-90.

[80] Kazemnia, A., M. Ahmadi, and M. Dilmaghani, Antibiotic resistance pattern of different Escherichia coli phylogenetic groups isolated from human urinary tract infection and avian colibacillosis. Iran Biomed J, 2014. 18(4): p. 219-24.

[81] Staji, H., M. Rassouli, and S. Jourablou, Comparative virulotyping and phylogenomics of Escherichia coli isolates from urine samples of men and women suffering urinary tract infections. Iran J Basic Med Sci, 2019. 22(2): p. 211-214.

[82] Bailey, J.K., et al., Distribution of Human Commensal Escherichia coli Phylogenetic Groups. Journal of clinical microbiology, 2010. 48(9): p. 3455-3456.

[83] Poirel, L., et al., Plasmid-mediated carbapenem and colistin resistance in a clinical isolate of Escherichia coli. 2016. 16(3): p. 281.

[84] Tischendorf, J., R.A. de Avila, and N. Safdar, Risk of infection following colonization with carbapenem-resistant Enterobactericeae: A systematic review. Am J Infect Control, 2016. 44(5): p. 539-43.

[85] Middendorf, B., et al., Instability of pathogenicity islands in uropathogenic Escherichia coli 536. 2004. 186(10): p. 3086-3096.

[86] Schneider, G., et al., Mobilisation and remobilisation of a large archetypal pathogenicity island of uropathogenic Escherichia coli in vitrosupport the role of conjugation for horizontal transfer of genomic islands. 2011. 11(1): p. 210. 